\title{
Identification of structural defects in composite materials by the thermal imaging non- destructive testing method
}

\author{
Andrey Kokurov ${ }^{1,3, *}$, Igor Odintsev ${ }^{1}$, Boris Chichigin ${ }^{2}$ and Dmitry Subbotin ${ }^{3}$ \\ ${ }^{1}$ Mechanical Engineering Research Institute of the Russian Academy of Sciences (IMASH RAN), 4 \\ Maly Kharitonyevsky Pereulok, 101990, Moscow, Russia \\ ${ }^{2}$ National Research University "Moscow Power Engineering Institute", 14 Krasnokazarmennaya str., \\ 111250, Moscow, Russia \\ ${ }^{3}$ PJSC "Tupolev", 17 Academician Tupolev Embankment, 105005, Moscow, Russia
}

\begin{abstract}
The article discusses the practical aspects of applying the thermal imaging non-destructive testing method of layered polymer composites. The specific purpose of the work is to demonstrate the possibilities of detecting in material and geometric identification of initial defects such as debonding.
\end{abstract}

\section{Introduction}

Currently, layered polymer composites are widely used in the creation of structural elements of various technical objects [1 - 3]. The ability to manufacture products in virtually any shape with predictable mechanical and mass-dimensional characteristics makes composite materials unique [4]. For the manufacture of high-tension elements of composite structures, most commonly, special sheet semi-finished products-prepregs are used $[5,6]$. They include a fibrous reinforcing filler and a binder. These days, carbon fibres are widely used as a filler [7], and epoxy resin as a binder. Autoclave technology is most often used to form products from prepregs. This process is quite complex and requires strict adherence to optimal technological conditions. Their violation can lead to the formation of various kinds of initial defects in the structure of the composite [8, 9]. The existence of defects adversely affects the product working ability, in particular, effectively reduce its durability.

Quite common defects are lack of adhesion in the structure of the material. One of the reasons for their occurrence is the presence of local areas on prepregs with unremoved protective polyethene film. Both the binder (resin) and the film residues are melted at such areas in the process of heating and sintering of the composite laminate. After cooling, the material retains partial adhesion between the laminas separated by the film. This complicates the detection of possible anomalies of the type described above. In particular, the application of known methods based on the analysis of deformation responses of the tested object to some small mechanical loading [10 - 12] is very limited. Therefore, the

* Corresponding author: and-kokurov@yandex.ru 
development of reliable tools for the identification of manufacturing defects in composite products is an urgent and sought-after task.

In this present work, we analyse the possibilities of using the thermal imaging nondestructive testing method to solve the problem $[13,14]$. The described approach is based on the registration and analysis of temperature responses on the surface of the composite structure to its small distant heating.

\section{Object of research}

Demonstration of common patterns of thermal imaging control of carbon fiber layered composites was carried out on specific examples. The test objects were rectangular plates with specially created internal structural anomalies of the described above type. Parent sheets for specimens were formed on the basis of unidirectional prepreg Torayca with filamentary of the T800 brand and 2592 binder [15]. The composite laminate as a whole consisted of 36 laminas $0.113 \mathrm{~mm}$ thick. Angles of layup orientation were (in degrees): $+45,0,-45,90,0,0,0,+45,0,-45,0,0,0,0,+45,90,0,0,0,0,90,+45,0,0,0,0,-45,0$, $+45,0,0,0,90,-45,0,+45$.

The modelling of defects in the material was carried out at the stage of laminat assembly by the intentional interlayer laying of fragments of a fluoroplastic film $(0.12 \mathrm{~mm}$ thick). It was expected that the replacement of polyethene with fluorocarbon as a film material would contribute to more conservative results. A prerequisite to this conclusion is the thermal properties of the materials represented in Table 1.

Table 1. Thermophysical properties of materials.

\begin{tabular}{|c|c|c|c|}
\hline \multirow{2}{*}{ Material properties } & \multicolumn{3}{|c|}{ Material } \\
\cline { 2 - 4 } & Prepreg & Fluoroplast & Polyethene \\
\hline Coefficient of thermal conductivity, $\lambda,\left[\mathrm{W} / \mathrm{m}^{\circ}{ }^{\circ} \mathrm{C}\right]$ & 1.13 & 0.23 & 0.29 \\
\hline Specific heat, $\mathrm{c} \cdot 10^{-3},\left[\mathrm{~J} / \mathrm{kg} \cdot{ }^{\circ} \mathrm{C}\right]$ & 0.74 & 0.92 & 2.09 \\
\hline Coefficient of thermal linear expansion, $\alpha \cdot 10^{6},\left[1 /{ }^{\circ} \mathrm{C}\right]$ & -0.4 & 0.9 & 1.8 \\
\hline
\end{tabular}

All composite specimens had the same dimensions but differed in shape, size and depth of location of the created defects, Figure 1. In total, four versions of the specimens were prepared. The differences between them are explained in Table 2.

Table 2. Variants of geometric characteristics of defects in specimens.

\begin{tabular}{|c|c|c|}
\hline Specimen & Shape and size $[\mathrm{mm}]$ & Depth, $\mathrm{h}[\mathrm{mm}]$ \\
\hline 1 & rectangle, $55 \times 83$ & 0.678 \\
\hline 2 & circule, $\varnothing 31$ & \\
\hline 3 & circule, $\varnothing 62$ & 1.356 \\
\hline 4 & circule, $\varnothing 62$ & \\
\hline
\end{tabular}
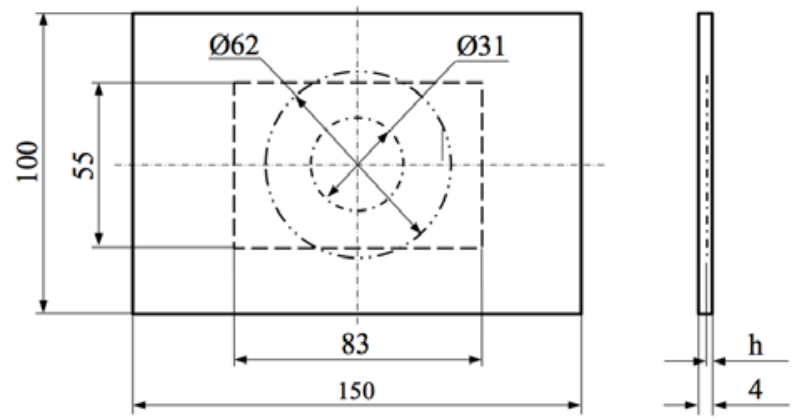

Fig. 1. Composite plate with identification of artificial defects. 


\section{Control procedures and means}

Thermal imaging defect detection is based on the principle of physical dependence of the temperature field on the surface of a briefly heated object on the heat transfer rate deep into the material. If the defect has a noticeable effect on this process, the recorded temperature distribution will have a local anomaly. This is because the thermal-physical properties of the unremoved polymer film are markedly different from the properties of the indefectible structure of the composite.

In principle, the thermograms registered in the experiment can be used to estimate the type and geometric characteristics of the hidden defect area by solving the inverse heat conduction problem. However, the practical implementation of such a procedure is quite difficult. The degree of reliability of the results thus obtained may turn out to be relatively low. In particular, this applies to the study of composite materials with a complex structure. At the same time, certain conclusions from the observed results of the heat flow pattern can be made based only on their qualitative analysis.

The test researches design is explained in Figure 2. The basic control systems components were a heating source and a heat emission detector. The specimens were heated by a halogen lamp with a capacity of $500 \mathrm{~W}$. The distance from the object of research to the heating source was $30 \mathrm{~mm}$. The duration of thermal irradiation of the specimens $\Delta t$ varied from 1 to 5 seconds in increments of 0.5 seconds and was controlled by an electronic timer TDM SQ1506-0002. Immediately after the completion of the thermal action, the temporal transformation of the heat flow pattern on the irradiated surface was recorded. For this purpose, we used a thermal imager NEC TH9100 PWV with a temperature resolution of $0.02{ }^{\circ} \mathrm{C}$. Its distance from the object of research was $500 \mathrm{~mm}$. The video information and the corresponding measured values were sequentially sent to the computer and stored in its memory. Analysis of the full array of incoming data was performed in a posteriori processing mode. NEC Image processor 4.7 software was used for this purpose.
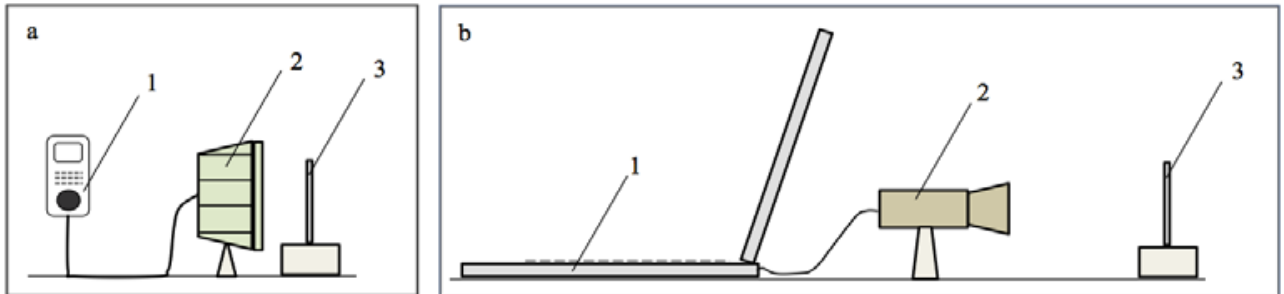

Fig. 2. Control system components. Heating scheme of the object of research (a): 1 - timer for the heating source, 2 - the heating source, 3 - the object of research. Scheme of active thermal control (b): 1 - personal computer, 2 - thermal imager, 3 - the object of research.

\section{Obtaining thermographic records of objects of research}

During the sequence of the tests, a significant dependence of the temperature contrast in the defect area on the duration of the testing heating $\Delta t$ was spotted. At its optimal value $\Delta t_{\text {opt }}$, registered thermographic records made it possible to confidently detect subsurface structural defects. The obtained thermograms were used to determine the shape and size of defects. When heated with a shorter duration, the observed patterns had reduced clarity. During the long-term keeping under irradiation, the specimens appeared to be overheated. It also prevented reliable identification of the anomalous area. The optimal heating time values are different for specimens with different defect parameters. Experimentally it was found that for the considered specimens with depths of defects in the range of $0.678-1.356$ 
$\mathrm{mm}$ the optimal heating time, depending on the depth, was 2.5-3.5 s. The thermographic records of the specimens surface, obtained in optimal durations of heating, are shown in Figure 3.

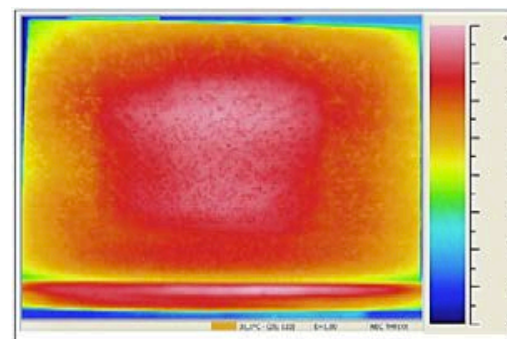

Specimen $1, \Delta t_{\text {opt }}=3.5 \mathrm{~s}$.

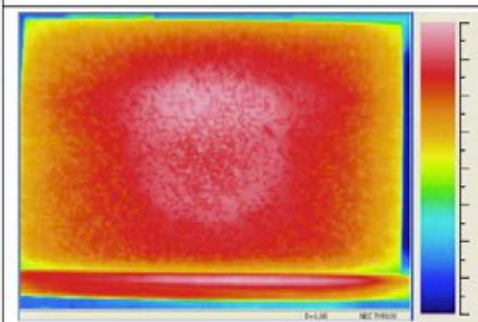

Specimen $3, \Delta t_{\text {opt }}=3.5 \mathrm{~s}$.

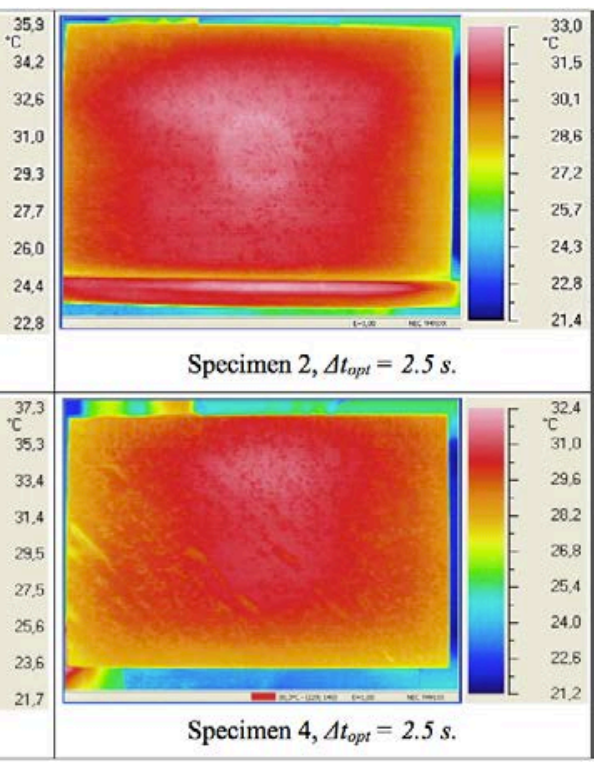

Specimen $4, \Delta t_{\text {opt }}=2.5 \mathrm{~s}$.

Fig. 3. Thermographic records of the specimens surface and defined optimal heat time.

\section{The defect sizing}

To calculate the section of defective areas, an automated algorithm was used, implemented in the National Instruments Vision Assistant software package. The algorithm included the following actions: procedure for selecting a saturation channel from a chromatic image, image smoothing with $3 \times 3$ averaging mask, binarization of the chromatic image by the adaptive threshold.

The value in the area of the local minimum of the image brightness histogram was chosen as a threshold. One local maximum was typical for the defective area and it was separated by local minimum from another local maximum existed for indefectible area. The resulting binary image was processed to obtain the parameters of the defect area.

The image processing procedure is illustrated in Figure 4. The most accurate data were obtained when the defects were located at a depth of $0.678 \mathrm{~mm}$. The identification and parameterization of the defect in the specimen with a round defect of $\varnothing 62 \mathrm{~mm}$ with a depth of $1.356 \mathrm{~mm}$ (on the heating side) turned out to be comparatively less indicative. Note that in this case, to achieve acceptable results, longer heating of the specimen was required.

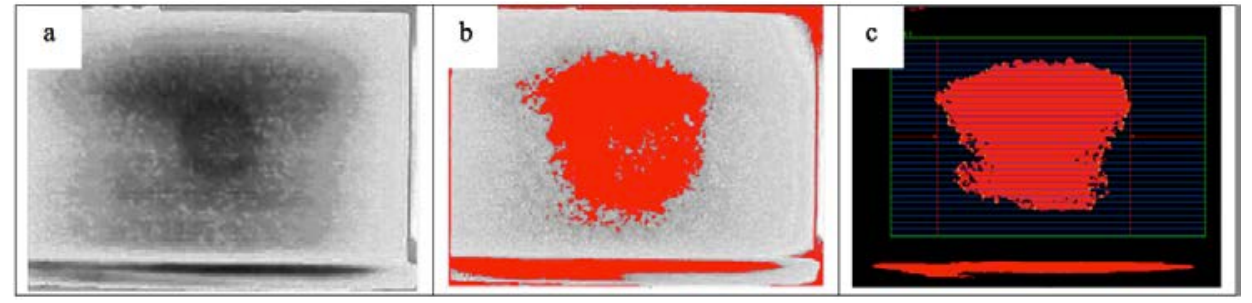

Fig. 4. Image processing procedures: a - saturation channel allocation, b - binarization, $\mathrm{c}$ - calculation of defect parameters from the image. 


\section{Conclusion}

The possibilities of the active thermal imaging control method applying to detect and identify of the structural defects in a polymer composite material are clearly demonstrated. Specific objects in the test experiments were carbon laminate plates with artificially created irregularities that model small areas on the prepreg with unremoved protective film. The shape and characteristic dimensions of anomalous areas were determined quite accurately by the thermal contrast on the surface of distant heated specimens. The efficiency of the described approach is determined by the modes optimization of testing composite laminat heating at different depths of the possible defect of the considered type.

This research is supported by Russian Foundation for Basic Research (Grant No. 18-08-00372 A).

\section{References}

1. G. Rathnakar, P. Pal, A review on the use and application of polymer composites in automotive industries, IJRASET, 3, 4 (2015)

2. M. Arif, M. Asif, I. Ahmed, Advanced composite material for aerospace application A review, IJEMS, 7, 2, (2017)

3. M. Toozandehjani, N. Kamarudin, Z. Dashtizadeh, E. Y. Lim, A. Gomes, C. Gomes, Conventional and advanced composites in aerospace industry: technologies revisited, AJAE, 5, 1 (2018)

4. A. K. Kaw, Mechanics of composite materials (CRC Press, Boca Raton, 2005)

5. P.K. Mallick, Fiber-reinforced composites: Materials, manufacturing, and design (CRC Press, Boca Raton, 2007)

6. S. G. Advani, E. M. Sozer, Process modeling in composites manufacturing (CRC Press, Boca Raton, 2010)

7. P. Morgan, Carbon fibers and their composites (CRC Press, Boca Raton, 2005)

8. R. A. Smith, Composite defects and their detection, Mater Sci Eng, 3, 1 (2009)

9. M.H. Hassan, A.R. Othman, S. Kamaruddin, A review on the manufacturing defects of complex-shaped laminate in aircraft composite structures, Int J Adv Manuf Techn, 91, 9-12 (2017)

10. A.R. Ganesan, Holographic and laser speckle methods in non-destructive testing, Proc. of the National Seminar \& Exhibition on Non-Destructive Evaluation (2009)

11. G. Gu, K. Wang, K. Zhou, X. Xu, Accurate measurement of composite laminates deflection using digital speckle pattern interferometry, Optik, 124, 20 (2013)

12. Q. Zhao, X. Dan, F. Sun, Y. Wang, S. Wu, L. Yang, Digital shearography for NDT: Phase measurement technique and recent developments, Appl. Sci, 8, 12 (2018)

13. M. Lizaranzu, A. Lario, A. Chiminelli, I. Amenabar, Non-destructive testing of composite materials by means of active thermography - Based tools, Infrared Phys. Technol., 71, July (2015)

14. A. J. R. da Silva, Detection and characterization of defects in composite materials using thermography, Programa Doutoral em Engenharia Mecânica (2016): https://pdfs.semanticscholar.org/4004/0968c464d2946985728764f7b457c5781f95.pdf

15. http://www.torayca.com/en/lineup/product/pro_003_01.html 